\title{
PENERAPAN KESELAMATAN DAN KESEHATAN KERJA PADA LABORATORIUM KONSTRUKSI SIPIL JURUSAN TEKNIK SIPIL - POLITEKNIK NEGERI MANADO
}

\author{
Syanne Pangemanan ${ }^{1}$, Jeanely Rangkang ${ }^{2}$ \\ 1,2 Jurusan Teknik Sipil, Politeknik Negeri Manado \\ Jl. Kampus Politeknik Ds. Buha Kec. Mapanget Kota Manado, SULUT \\ ${ }^{1}$ Email: syannepangemanan70@gmail.com \\ 2Email: jeanelyr@yahoo.com
}

\begin{abstract}
ABSTRAK
Laboratorium Konstruksi Sipil merupakan sarana untuk melaksanakan kegiatan praktek kerja mahasiswa. Laboratorium Konstruksi Sipil dengan segala kelengkapan peralatan dan bahan merupakan tempat berpotensi menimbulkan bahaya kepada para penggunanya yaitu dosen, teknisi dan mahasiswa di dalamnya jika tidak dibekali dengan pengetahuan mengenai kesehatan dan keselamatan kerja.

Biaya untuk membangun keselamatan dan kesehatan kerja, biaya untuk membeli alat-alat pengamanan memang cukup besar. Akan tetapi keselamatan dan kesehatan kerja juga akan lebih terjamin. Kemampuan dan ketrampilan pekerja harus ditingkatkan melalui pendidikan dan pelatihan sehingga dapat mengikuti laju perkembangan ilmu pengetahuan dan teknologi Alat penanggulangan musibah harus ditingkatkan agar malapetaka yang diakibatkan oleh penerapan teknologi maju tidak sampai meluas dan merusak. Tapi saat ini penggunaan alat-alat pengaman untuk pelaksanaan praktek di Laboratorium Konstruksi Sipil Jurusan Teknik Sipil Politeknik Negeri Manado masih kurang.

Tujuan khusus diseminasi produk teknologi ke masyarakat yang ingin dicapai adalah (1) Melindungi dan menjamin keselamatan setiap dosen, teknisi, mahasiswa dan orang lain di tempat kerja; (2) Pelatihan K3 untuk dosen dan teknisi (3) Adanya Buku Panduan K3 untuk laboratorium Konstruksi Sipil.

Untuk mencapai tujuan tersebut diatas, maka melalui indikator luaran yang ditargetkan adalah : (1) Perlengkapan K3 yaitu Alat Pelindung Diri (APD) berupa Helm, Masker, Rompi, Sarung tangan dan Sepatu safety (2) Buku Panduan K3; (3) Jasa Pelatihan K3 untuk Dosen dan Teknisi dan (4) Publikasi pada media massa on-line lokal.
\end{abstract}

Kata kunci : penerapan, perlengkapan, panduan, K3

\begin{abstract}
Civil Construction laboratories are the means to conduct student work practices. Civil Construction Laboratory with all equipment and materials is a place of potential cause danger to the users of lecturers, technicians and students in it if not equipped with knowledge about health and Occupational safety.

The cost to build occupational safety and health, the cost to buy security tools is quite large. However, occupational safety and health will also be assured. Workers 'skills and skills must be increased through education and training so as to follow the pace of development of science and technology disaster relief tools should be improved to make the catastrophe caused by the implementation of Advanced technology is not until widespread and destructive. But currently the use of safety equipment for the implementation of practice in the Civil Construction Laboratory of Civil Engineering Department of Manado State Polytechnic is still lacking.
\end{abstract}


The specific purpose of dissemination of technological products to the communities to be achieved is (1) protecting and guaranteeing the safety of any lecturers, technicians, students and other people in the workplace; (2) Training K3 for lecturers and Technicians (3) The K3 Handbook for Civil Construction Laboratories.

To achieve these objectives, then through the targeted external indicators are: (1) K3 equipment is personal protective equipment (APD) in the form of helmets, masks, vests, gloves and safety shoes (2) K3 Handbook, (3) Training services of K3 for lecturers and technicians and (4) publications on Local on-line mass media.

Keywords: application, equipment, guide, $K 3$

\section{PENDAHULUAN}

Politeknik Negeri Manado merupakan salah satu dari Politeknik yang dibangun oleh Pemerintah dalam rangka memperluas akses pemerataan pendidikan untuk meningkatkan percepatan pembangunan secara merata. Diresmikan oleh Presiden RI pada tanggal 19 Juli 1988 dengan nama Politeknik Engineering Universitas Sam Ratulangi Manado. Politeknik Engineering Universitas Sam Ratulangi Manado menjadi mandiri dalam penyelenggaraan pendidikan dan memisahkan diri dari Universitas Sam Ratulangi Manado pada Januari 1999 dan berubah nama menjadi Politeknik Negeri Manado.

Politeknik Negeri Manado melaksanakan proses belajar mengajar dengan Sistem Penjaminan Mutu yang berdasarkan Standar ISO 9001 : 2008 yang dijabarkan pada berbagai Standar Operasional Prosedur yang menjadi pedoman pelaksanaan seluruh kegiatan akademik yang harus ditaati oleh seluruh komponen yang terlibat. Sebagai Lembaga Pendidikan Vokasi (Terapan), upaya untuk meningkatkan kualitas proses dan manajemen pendidikan serta kualitas output pendidikan itu sendiri telah dilakukan dengan berbagai cara, dan salah satu aspek yang sangat penting adalah peningkatan kompetensi pembelajaran di laboratorium. Berbagai peraturan dan kebijakan yang mendukung berbagai upaya tersebut telah dilahirkan dan dilaksanakan, serta mulai menampakkan hasilnya.

Laboratorim Konstruksi Sipil merupakan salah satu fasilitas yang dimiliki Jurusan Teknik Sipil Politeknik Negeri Manado. Laboratorium Konstruksi Sipil ini menunjang kegiatan mahasiswa Program Studi Diploma III Teknik Sipil dan Program Studi Diploma IV Sarjana Terapan Konstruksi Bangunan Gedung dan Teknik Konstruksi Jalan dan Jembatan dalam pelaksanaan Praktikum. Selain sebagai fasilitas penunjang akademik mahasiswa, Laboratorium Konstruksi Sipil juga melayani pekerjaan struktur suatu 
bangunan/gedung, jalan dan jembatan dari suatu instansi baik swasta maupun pemerintah sesuai dengan prosedur yang berlaku dimana pelaksanaannya ditangani oleh Tim.

Aktifitas yang dilaksanakan oleh Laboratorium Konstruksi Sipil adalah Praktikum untuk ketiga program studi yang ada di Jurusan Teknik Sipil dan beberapa potensi kegiatan yang dapat dilakukan yaitu pelatihan/workshop beton dan baja untuk bangunan gedung dan jalan jembatan. Fasilitas infrastruktur yang ada di laboratorium konstruksi sipil adalah Ruang kerja bengkel, Ruang praktek, Ruang Kepala Laboratorium, Ruang Teknisi, Ruang Kuliah dan Ruang tunggu mahasiswa.

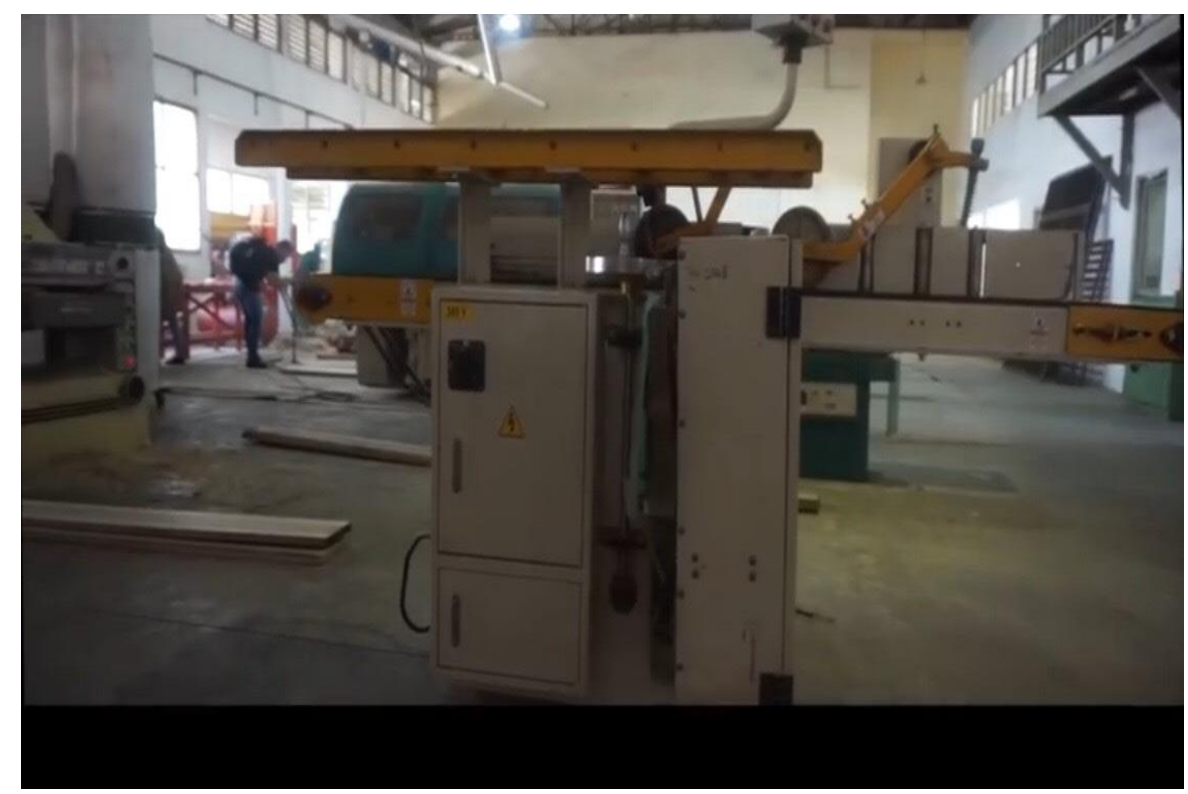

Gambar 1. Ruang Praktek Lab. Konstruksi Sipil

Berdasarkan hasil survey yang dilaksanakan di Laboratorium Konstruksi Sipil Jurusan Teknik Sipil Politeknik Negeri Manado pada Bulan Februari 2019 dan bertemu langsung dengan Kepala Laboratorium dan beberapa teknisi yang ada, maka di dapat persoalan dalam pelaksanaan praktikum antara lain penerapan K3 dalam praktek, dalam hal ini tidak tersedianya perlengkapan K3 dalam proses perkuliahan praktek.

Penerapan Keselamatan dan Kesehatan Kerja sangat dibutuhkan dalam proses perkuliahan praktek di Laboratorium Konstruksi Sipil. Kepala laboratorium, teknisi dan mahasiswa belum menggunakan Alat Pelindung Diri pada saat pelaksanaan praktek, panduan dan standar-standar acuan K3 juga belum tersedia.

Masalah prioritas yang dilaksanakan melalui kegiatan diseminasi produk teknologi ke masyarakat ini, adalah : 
1. Permasalahan fisik yang didapati dan menjadi pembatasan permasalahan yang ditinjau pada Laboratorium Konstruksi Sipil ini yaitu mengenai sarana dan prasarana Laboratorium Konstruksi Sipil ini belum memadai. Perlengkapan K3 yaitu Alat Pelindung Diri (APD) seperti helm, masker, kacamata, sarung tangan, rompi dan sepatu safety tidak tersedia. Hal ini dikarenakan tidak adanya dana yang cukup untuk pembelian APD tersebut.

2. Permasalahan non fisik adalah mengenai sumber daya manusia dalam hal ini dosen dan teknisi yang masih kurang memahami tentang Penerapan K3 dalam kegiatan proses pembelajaran praktek. Hal ini disebabkan karena Kepala Laboratorium, Dosen dan teknisi belum diikut sertakan dalam pelatihan K3 untuk proses pendampingan pembelajaran praktek di laboratorium.

Dan melalui kegiatan diseminasi produk teknologi ke masyarakat diharapkan untuk dapat menjawab berbagai permasalahan fisik dan non fisik yang ada pada laboratorium konstruksi sipil jurusan teknik sipil, yang tentunya sangat berpengaruh terhadap peningkatan keselamatan dan kesehatan kerja para pengguna laboratorium untuk dapat melakukan praktek dengan aman dan nyaman, resiko yang mungkin muncul dapat dihindari. Dan dapat melakukan praktek dengan merasa nyaman dan betah, sehingga tidak mudah capek.

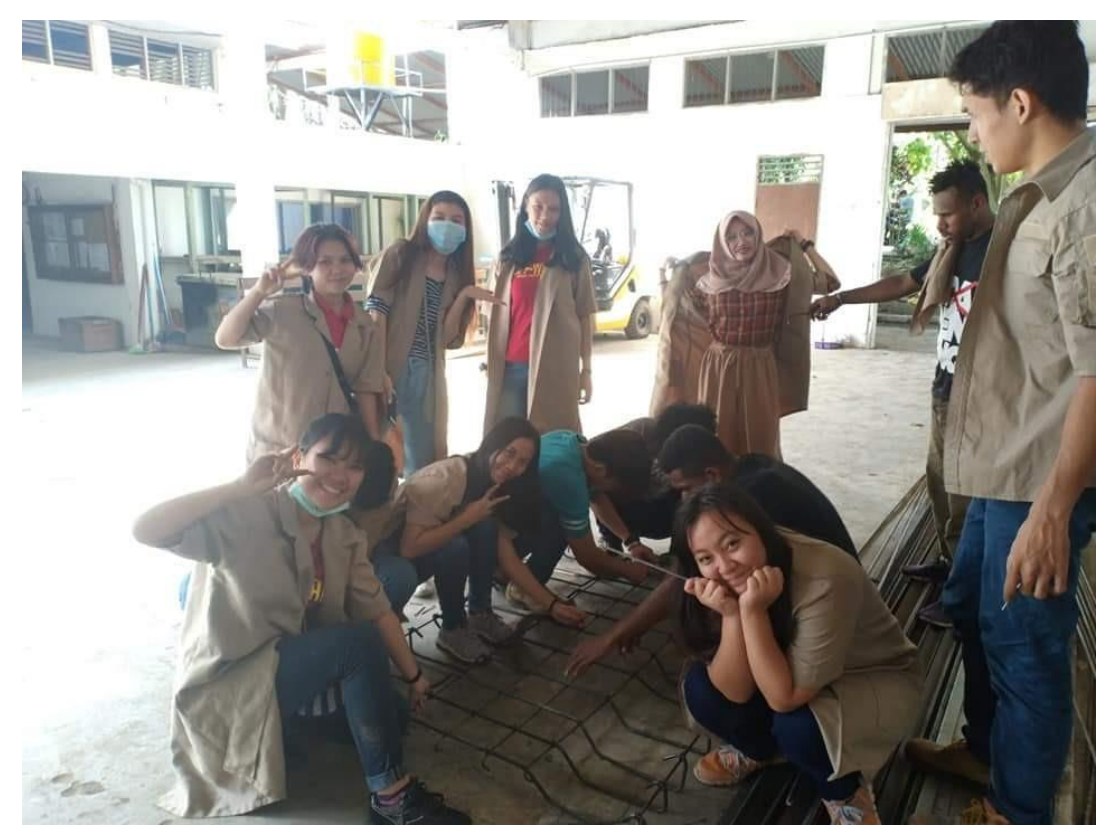

Gambar 2. Praktikum di Laboratorium Konstruksi Sipil yang tidak menggunakan APD 


\section{METODE PELAKSANAAN}

Pelaksanaan program diseminasi produk teknologi ke masyarakat ini bekerjasama dengan Laboratorium Konstruksi Sipil Jurusan Teknik Sipil Politeknik Negeri Manado. Kelompok mitra melaksanakan pelayanan pendidikan pada jenjang pendidikan tinggi. Pada kunjungan awal tim menjelaskan tentang maksud kerjasama ini, yaitu untuk mengimplementasikan hasil yang diperoleh pada penelitian tahun 2018 lalu. Kepala laboratorium teknik sipil merasa sangat bangga dan berharap agar bisa memperoleh kerjasama ini karena kelompok mitra ini tidak mempunyai standard an APD yang memadai penunjang pelaksanaan pembelajaran praktek laboratorium teknik sipil. Data-data yang dibutuhkan untuk mengolah proposal diseminasi ini juga diberikan dengan jelas dan rinci dari kelompok mitra dalam hal ini Kepala Laboratorium Teknik Sipil Politeknik Negeri Manado.

Untuk menjawab permasalahan yang ada, maka TIM akan bekerjasama dengan kelompok Mitra dalam hal ini Laboratorium Konstruksi Sipil, Jurusan Teknik Sipil Politeknik Negeri Manado. Pihak-pihak yang terlibat dalam pelaksanaan program diseminasi ini adalah Kepala Laboratorium Teknik Sipil sebagai penanggung jawab, dosen pengajar proses pembelajaran praktek sebagai instruktur, teknisi sebagai pendamping instruktur, dan mahasiswa yang terlibat sebagai pelaku atau pengguna jasa laboratorium.

Untuk menerapkan keselamatan dan kesehatan kerja di lingkungan pendidikan, maka sebaiknya disiapkan APD yang sesuai dengan kebutuhan dalam proses pembelajaran di laboratorium dan dilaksanakan pelatihan penggunaan APD. Yang dilakukan melalui pelatihan ini yaitu simulasi tentang cara penggunaan APD yang baik, sehingga kelompok mitra dapat bekerja secara lebih baik lagi dengan rasa aman dan nyaman. Metode yang digunakan dalam pelatihan ini adalah teori dan praktek. Pelatihan K3 ini diberikan dalam satu pertemuan sebanyak 2 jam. Tim kerja program diseminasi ini akan menyiapkan materi pelatihan yang dibutuhkan seperti buku Undang-Undang tentang K3 dan standar-standar, serta perangkat APD yang akan digunakan. Hasil kegiatan pelatihan ini akan dimonitoring dan dievaluasi selama kegiatan diseminasi ini berlangsung.

Teknologi yang akan didesiminasikan pada pengabdian masyarakat ini adalah berupa aplikasi hasil penelitian yang telah selesai dilakukan pada tahun 2018. Hasil dari penelitian tersebut dapat digunakan untuk membantu proses pembelajaran praktikum di Laboratorium Konstruksi Sipil Jurusan Teknik Sipil Politeknik Negeri Manado. 
Hal ini dimaksudkan agar pada saat proses pembelajaran praktikum dosen, teknisi dan mahasiswa dapat dengan mudah mendapatkan Undang-Undang dan Standar-Standar Keselamatan dan Kesehatan Kerja (K3), serta Alat Pelindung Diri, sehingga rasa aman dan nyaman dalam kegiatan praktek.

Sebagaimana telah dijelaskan pada Bab I sebelumnya, skala prioritas masalah yang telah disusun dengan maksud untuk mendapatkan solusi melalui kegiatan diseminasi ini, maka susunan kegiatan pada gambar 3.1. dibawah ini adalah gambaran metode pelaksanaan kegiatan yang dimaksud yang sudah disosialisasikan kepada kelompok mitra.

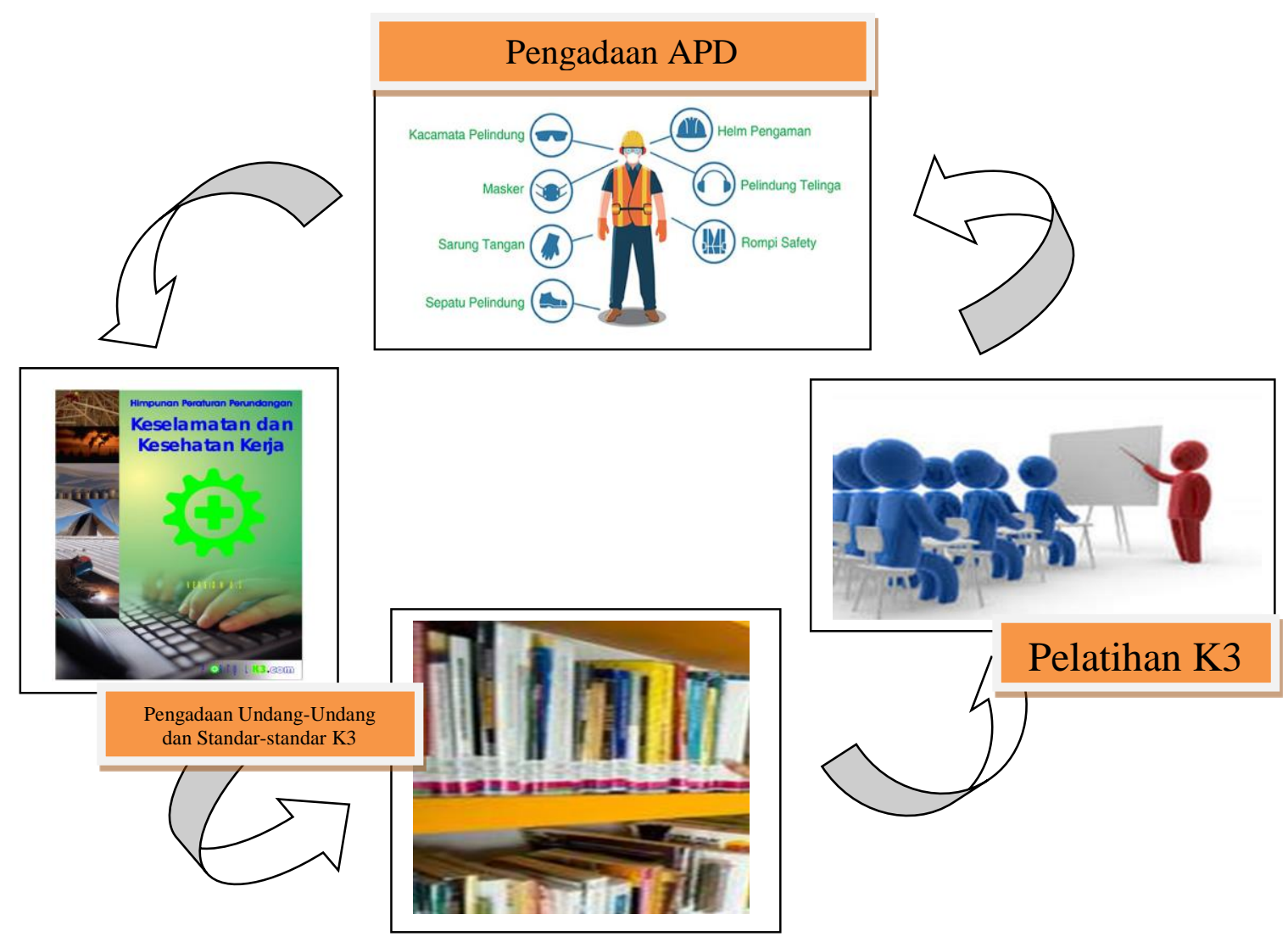

Gambar 3. Gambaran Metode Pelaksanaan Kegiatan

Pelaksanaan Pengabdian pada masyarakat program diseminasi produk teknologi ke masyarakat ini tidak lepas dari kontribusi kelompok mitra. Kelompok mitra berkontribusi mulai dari pembuatan proposal yaitu dengan memberikan data-data yang dibutuhkan dan menandatangani kesediaan bekerjasama. Selanjutnya dalam pelaksanaan diseminasi ini, 
kelompok mitra akan menyiapkan ruangan dan fasilitas penunjang lainnya yang dibutuhkan dalam pelatihan K3 sampai dengan simulasi dan praktek penggunaan APD. Pada penyusunan laporan akhir juga, kelompok mitra sudah bersedia untuk membantu dalam hal monitoring dan evaluasi pelaksanaan diseminasi dengan memberikan data yang dibutuhkan. Selanjutnya juga kelompok mitra diseminasi ini senantiasa bersedia dan berkomitmen untuk menjaga, merawat dan menggunakan hasil dari kerjasama ini untuk meningkatkan Keselamatan dan Kesehatan Kerja di Laboratorium Teknik Sipil Jurusan Teknik Sipil Politeknik Negeri Manado.

Tahap evaluasi pelaksanaan dan keberlanjutan program ini bertujuan untuk mengetahui seberapa besar peningkatan keselamatan dan kesehatan kerja di laboratorium yang dapat dilihat dari segi kuantitatif dan kualitatif. Selanjutnya pada tahap pendampingan dilakukan pengadaan tempat penyimpanan APD tersebut dan rambu-rambu K3 sebagai langkah untuk mengaplikasikan K3 di lingkungan Politeknik Negeri Manado khususnya pada pembelajaran praktek. Program yang terbentuk ini akan diperkenalkan kepada laboratorium yang ada di Jurusan Teknik Sipil bahkan yang ada di Politeknik Negeri Manado.

\section{HASIL DAN PEMBAHASAN}

Hasil yang dicapai oleh Tim kegiatan Diseminasi Produk Teknologi Ke Masyarakat Tahun 2019 kepada kelompok mitra adalah sebagai berikut :

1. Pelatihan K3 bagi Dosen, Teknisi dan Laboratorium serta mahasiswa di Laboratorium Konstruksi Sipil Politeknik Negeri Manado tentang Penerapan Keselamatan dan Kesehatan Kerja agar tercipta laboratorium yang aman dan nyaman dalam pelaksanaan proses pembelajaran praktikum.

2. Menyediakan beberapa Buku Pedoman dan Standar K3 yang berlaku untuk digunakan di Laboratoriam sebagai panduan melaksanakan Pembelajaran di Laboratorium sesuai kebutuhan laboratorium Konstruksi.

3. Memperlengkapi Dosen, Teknisi dan Mahasiswa dengan Alat Pelindung Diri (APD) dalam pelaksanaan proses pembelajaran praktikum.

Berkat kerjasama Tim Program Kemitraan Masyarakat dengann Kelompok Mitra, sehingga luaran yang telah dicapai untuk Sekolah Dasar ini adalah sebagai berikut : 1. Meningkatnya pengetahuan tentang Keselamatan dan Kesehatan Kerja. 
2. Pemahaman tentang Panduan Pelaksanaan K3 sesuai kebutuhan Laboratorium Konstruksi Sipil.

3. Tersedianya Alat Pelindung Diri yang digunakan oleh Dosen, Teknisi dan Mahasiswa dalam proses pembelajaran praktikum.

4. Publikasi pada jurnal pengabdian dan media massa on-line lokal.

\section{KESIMPULAN}

Kegiatan Diseminasi Produk Teknologi Ke Masyarakat telah dilaksanakan oleh Tim pada kelompok mitra di Laboratorium Konstruksi Sipil Jurusan Teknik Sipil Politeknik Negeri Manado, sehingga dapat disimpulkan antara lain :

1. Agar tercipta laboratorium yang aman dan nyaman dalam pelaksanaan proses pembelajaran praktikum maka diterapkan Keselamatan dan Kesehatan kerja di Laboratorium Konstruksi Sipil Jurusan Teknik Sipil Politeknik Negeri Manado dengan mengadakan pelatihan K3 bagi Dosen, Teknisi dan Laboratorium serta mahasiswa merupakan suatu hal yang wajib dilakukan.

2. Harus disiapkan Buku Pedoman dan Standar K3 yang berlaku untuk digunakan di Laboratoriam sebagai panduan melaksanakan Pembelajaran di Laboratorium sesuai kebutuhan laboratorium Konstruksi.

3. Perlengkapan Alat Pelindung Diri (APS) untuk Dosen, Teknisi dan Mahasiswa dalam pelaksanaan proses pembelajaran praktikum masih belum memadai.

\section{REKOMENDASI}

Dari hasil kegiatan Diseminasi Produk Teknologi Ke Masyarakat, maka tim merekomendasikan hal-hal berikut :

1. Manajemen tingkat tinggi harus menjamin bahwa pelaksanaan praktikum di laboratorium Konstruksi Sipil Jurusan Teknik Sipil Politeknik Negeri Manado harus terlaksana dengan benar sesuai dengan pedoman dan standart yang berlaku.

2. Buku Pedoman dan Standar K3, harus tersedia dan disosialisasikan kepada mahasiswa sebelum pelaksanaan praktikum.

3. Tersedianya Alat Pelinding Diri yang memadai dan mencukupi untuk semua Dosen, Teknisi dan mahasiswa yang melaksanakan praktikum. 


\section{UCAPAN TERIMAKASIH}

Ucapan terimakasih disampaikan kepada Direktur Politeknik Negeri Manado Ir. Ever N. Slat, MT, Kepala Pusat Penelitian dan Pengabdian Pada Masyarakat Politeknik Negeri Manado Dr. Tineke Saroinsong, ST., M.Eng, Ketua Jurusan Teknik Sipil Politeknik Negeri Manado Noldie E. Kondoj, ST.,MT, Kepala Laboratorium Konstruksi Sipil Jurusan Teknik Sipil Politeknik Negeri Manado Vicky A. Assa, SST., MT, serta Teknisi, Laboran dan Mahasiswa Jurusan Teknik Sipil dan semua pihak yang tidak dapat kami sebutkan satu persatu yang telah membantu terlaksananya kegiatan Diseminasi Produk Teknologi Kepada Masyarakat ini.

\section{DAFTAR PUSTAKA}

Anizar. (2009). Teknik Keselamatan dan Kesehatan Kerja di Industri. Yogyakarta: Graha Ilmu.

Cecep Dani Sucipto. (2014). Keselamatan dan Kesehatan Kerja. Yogyakarta: Gosyen

Daryanto. (2010). Keselamatan Kerja Peralatan Bengkel dan Perawatan Mesin. Bandung: Alfabeta. Kementerian Sekretariat Negara. 2012. PP RI No. 50 Tahun 2012 tentang Sistem Manajemen Keselamatan dan Kesehatan Kerja. Jakarta:

Departemen Tenaga Kerja. (1970). Undang-undang Republik Indonesia No. 1 tahun 1970 tentang Keselamatan Kerja. Jakarta: Departemen Tenaga Kerja.

Departeman Tenaga Kerja. (1970). Undang-undang Republik Indonesia No. 1 Tahun 1970 tentang Keselamatan Kerja. Jakarta: Departeman tenga Kerja.

Direktorat Riset Dan Pengabdian Kepada Masyarakat, Direktorat Jendral Penguatan Riset Dan Pengembangan, Kementerian Riset, Teknologi, dan Pendidikan Tinggi, 2017, "Buku Panduan Pelaksanaan Penelitian Dan Pengabdian Kepada Masyarakat Di Perguruan Tinggi”, Edis XII, Tahun 2018, http://www.ristekdikti.go.id/

Kemensesneg Kementerian Tenaga Kerja dan transmigrasi Republik Indonesia (2013). Cegah Kecelakaan Kerja, Kemnakertrans Kerahkan 138 Mobil URC. Diakses dari http:/menteri.depnakertrans.oo.id?show=news\&news.id=118. Pada tanggal 6 November 2015.

Noviandry, Ilham.2013. Faktor-Faktor yang Berhubungan dengan Perilaku Pekerja dalam Penggunaan Alat Pelindung Diri (APD) pada Industri 96 Pengelasan Informal di Kelurahan Gondrong, Kecamatan Cipondoh, Kota Tangerang Tahun 2013. Jakarta: Skripsi Program Sarjana Kesehatan Masyarakat Universitas Islam Negeri Syarif Hidayatullah Jakarta. Dapat diakses di http://repository.uinjkt.ac.id/dspace/bitstream/123456789/24269/1/Ilha m\%20Noviandry-fkik.pdf . Diakses pada 14 Februari 2018

OHSAS 18001. 1998. Sistem Manajemen Keselamatan dan Kesehatan Kerja. Di akses dari http://www.dckonsultan.com/downloads/Brosur_OHSAS_18001.pdf pada tanggal 15 Februari 2018.

Suma'mur. (1989). Keselamatan Kerja dan Pencegahan Kecelakaan. Cetakan Keempat. Jakarta : CV. Haji Mas Agung.

Suma`mur. (1996). Higiene Perusahaan dan Kesehatan Kerja (HIPERKES). Jakarta: Sagung 
Seto.

Tasliman. H.A. (1993). Keselamatan dan Kesehatan Kerja (Bahan Ajar). Yogyakarta: UNY. Tarwaka. 2008. Keselamatan Dan Kesehatan Kerja. Harapan Press, Surakarta

Tigor Tambunan. (2007). Personal Protective Equipment. Yogyakarta: Graha-Ilmu Yogyakarta

Widodo Siswowardojo. (2003). Norma Kesehatan dan Keselamatan Kerja Karyawan. Edisi 1. Yogyakarta

Wijono, Joko (2007). Manajemen Program dan kepemimpinan kesehatan.

Wowo Sunaryo Kuswana. (2015). Mencegah Kecelakaan Kerja. Bandung: PT Remaja Rosdakarya 